\title{
O papel da educação não formal (de adultos) na promoção do envelhecimento bem-sucedido
}

\author{
Maria da Conceição Pinto Antunes ${ }^{1}$ \\ ORCID: 0000-0003-3569-6020 \\ Ana Catarina Macedo² \\ ORCID: 0000-0002-9340-4877
}

\section{Resumo}

No âmbito de uma concepção de educação permanente e comunitária, ou educação ao longo da vida, o nosso ensaio propõe-se evidenciar a importância da educação de adultos na promoção do envelhecimento bem-sucedido, com base em um projeto de investigação/ intervenção concretizado numa Instituição Particular de Solidariedade Social, no norte de Portugal. 0 projeto integrou um grupo de vinte e cinco adultos em processo de aposentadoria e pré-aposentadoria com idades compreendidas entre os cinquenta e seis e setenta e cinco anos. Compreendeu-se que o paradigma de investigação/intervenção mais adequado a este projeto era o qualitativo, interpretativo hermenêutico e a investigaçãoação participativa, enquanto promotora da participação e motivação de todos os agentes sociais, evidenciou-se como a metodologia mais adequada para o seu desenvolvimento. Considerando os interesses, necessidades e potencialidades dos participantes, a intervenção decorreu por meio da implementação de três oficinas: Informática; Pedagógica e Vida Saudável; e Temática, onde foram desenvolvidas atividades com base em metodologias ativas e participativas que permitiram estimular uma participação voluntária e efetiva, proporcionando momentos de aprendizagem, convívio e lazer, transformando o cotidiano dos participantes. 0 projeto destaca o processo de intervenção educativa com adultos idosos e evidencia resultados positivos ao nível das aprendizagens, do relacionamento interpessoal e aumento do bem-estar, apontando para a premência da implementação generalizada da educação na terceira idade com vista à promoção de um envelhecimento bem-sucedido.

\section{Palavras chave}

Educação de adultos - Intervenção comunitária - Envelhecimento bem-sucedido.

1- Universidade do Minho, Braga, Portugal. Contato: mantunes@ie.uminho.pt.

2- Universidade do Minho Braga, Portugal. Contato: acatarinam@hotmail.com. 


\title{
The role of informal (adult) education in the promotion of successful ageing
}

\begin{abstract}
Framed by a community-focused and ongoing, or lifelong, vision of education, this paper aims to demonstrate the importance of adult education in the promotion of successful ageing, based on an action research project at a Private Institution for Social Solidarity (Instituição Particular de Solidariedade Social) in Northern Portugal. The project involved a group of twenty-five retired and partially retired adults, aged fifty-six to seventy-five. Qualitative and hermeneutic interpretive research paradigms were considered to be the most appropriate for this project, while the preferred methodology was participatory action research, for its capacity to promote participation and engage the social actors involved. In light of the interests, needs and potential of the participants, the action took the form of three workshops: Computer Skills; Pedagogy \& Healthy Living and a Topical workshop. These consisted of activities based on active, participative methodologies that foster effective, willing participation, providing opportunities for learning, socialising and recreation and transforming the daily lives of the participants. The project highlights the processes involved in educational intervention programmes for older adults and shows positive outcomes in terms of learning, interpersonal relationships, and improved wellbeing, signalling the urgent need for widespread third age educational provision as a means of promoting successful ageing.
\end{abstract}

\section{Keywords}

Adult education - Community action - Successful ageing.

\section{Introdução}

Uma nova forma de perspetivar o envelhecimento

Não obstante o fato de na velhice o organismo humano se revelar mais vulnerável, o processo de envelhecimento tem vindo a desligar-se, cada vez mais, da sua conotação negativa, em consequência dos resultados de uma vasta panóplia de investigações (ABELES; GIFT; ORY, 1994; BALTES; BALTES, 1990; HAZARD, 1995; ROWE; KAHN, 1997a) que, desde há muito tempo, têm vindo a abordar a questão do envelhecimento de um ponto de vista positivo. Esta vertente de investigação, fortemente sustentada pela MacArthur Foundation Research Network On Successfull Ageing, nos Estados Unidos, nos anos 80, mas que, rapidamente, se estendeu a outros países, na sequência do estudo de Rowe e Kahn (1987), tem vindo a construir um novo paradigma na forma de entender e 
viver o envelhecimento, baseada não apenas nas perdas e declínios mas numa abordagem integral, valorizando as dimensões biológicas, psicológicas e sociais.

Com base no seu estudo, Rowe e Kahn (1987) propõem uma definição de "envelhecimento normal" que entendem como não patológico, mas distinguindo duas formas de envelhecer: "normal", ou seja, relativa a indivíduos que revelam um perfil de envelhecimento não patológico mas de alto risco de doença; e "bem-sucedida", relativa a indivíduos cujo perfil de envelhecimento revela baixo risco de doença e elevado potencial de funcionamento (ROWE; KAHN, 1987). Decorrida uma década, após o primeiro estudo, orientando a sua linha de investigação no sentido de compreender os critérios e determinantes do envelhecimento bem-sucedido, Rowe e Kahn (1997a, 1997b, p. 38) apresentam uma nova abordagem do conceito de envelhecimento bem-sucedido mais alargada que congrega a conjugação de três componentes: “(...) i) baixo risco de doença e de incapacidades relacionadas com a doença; ii) elevado funcionamento físico e mental; iii) envolvimento ativo com a vida".

Não obstante pequenas derivações, ainda hoje, a comunidade científica bem como a opinião pública consideram que falar de envelhecimento bem-sucedido pressupõe responder positivamente a três critérios básicos: saúde, elevado nível de funcionamento físico e cognitivo e participação social (FONTAINE 2000; JACOB, 2007; PAÚL; FONSECA, 2005; RIBEIRO; PAÚL, 2011; ROWE; KAHN, 1997a, 1979b). Na concepção de envelhecimento bem-sucedido de Rowe e Kahn (1997a, 1997b) subjaz a ideia de que o processo de envelhecimento não é determinado apenas por fatores e/ou potencialidades de natureza genético-biológica. Este processo é, também, fortemente determinado por fatores socioculturais (BALTES, 1987), pelo envolvimento ativo com a vida e pela ação e intervenção humana que pode, ou não, ser favorável a um processo de envelhecimento bem-sucedido.

Esta concepção de entender o processo de envelhecimento é corroborada e robustecida pelas investigações pioneiras no âmbito da psicologia do desenvolvimento, de modo particular, com os estudos de Baltes (1987) e Baltes e Baltes (1990) que propõem uma caracterização do envelhecimento em três categorias: i) patológico - relativo a casos onde se verificam doenças, patologias e disfuncionalidades do desenvolvimento; ii) normal relativo a alterações associadas e inevitáveis do envelhecimento; iii) ótimo - relativo a um envelhecimento caracterizado por baixo risco de doenças e incapacidades, elevado nível de funcionamento físico e social e envolvimento ativo com a vida (BALTES, 1987). 0 envelhecimento ótimo aparece conectado à nova concepção de que o potencial de desenvolvimento está presente ao longo de todas as fases da vida, constituindo-se numa dinâmica entre crescimento (ganhos) e declínio (perdas) (BALTES, 1987; BALTES; BALTES, 1990). Assim, como em qualquer outra fase da vida, na velhice há um equilíbrio entre ganhos e perdas, que será tanto mais favorável quanto maior for a opção humana por atividades e comportamentos potenciadores de um processo de envelhecimento bem-sucedido. Neste enquadramento, para que o desenvolvimento humano continue a verificar-se durante o processo de envelhecimento e velhice será necessário disponibilizar ações, programas, projetos educativos/culturais promotores de aprendizagens, conhecimentos e habilidades que 
funcionem como benefícios ou potencialidades de enfrentamento das novas condições de vida, ou seja, como ganhos passíveis de compensar as perdas inerentes ao processo do envelhecimento.

Os documentos europeus mais recentes, cujo princípio orientador se centra na capacitação ou empoderamento dos indivíduos para um envelhecimento bem-sucedido (EUROPEAN COMMISSION, 2012; WORLD HEALTH ORGANIZATION, 2001, 2002, 2013; DIREÇÃO GERAL DE SAÚDE, 2015; FUNDAÇÃO CALOUSTE GULBENKIAN, 2014), seguem, em nossa opinião, essa mesma linha de pensamento, orientando para a ideia de que o envelhecimento bem-sucedido é, também, uma questão de educação.

A evolução dos conceitos "envelhecimento" e "educação" parecem ter convergido no sentido de uma aliança que, nos dias de hoje, se evidencia cada vez mais reforçada na literatura da área e nos documentos internacionais referindo a educação como fator importantíssimo na promoção do envelhecimento bem-sucedido.

\section{A educação na e para a terceira idade}

Nos nossos dias, ao conceito de educação está subjacente o conceito de Educação ao Longo da Vida, entendido no seu sentido genuíno de "life long education and learning”, surgido pela primeira vez na Declaração de Nairobi (UNESCO, 1976). A partir deste documento a educação é entendida como um processo permanente e comunitário, motor do desenvolvimento individual e coletivo. Essa concepção de educação pressupõe que o ser humano é um ser inconcluso, um ser a fazer-se e (re)fazer-se em função dos acontecimentos que vai experienciando e dos novos conhecimentos e aprendizagens que vai adquirindo ao longo do seu percurso de vida. Neste horizonte de compreensão, a concepção de Educação ao Longo da Vida pressupõe uma reestruturação do sistema educativo existente (predominantemente formal, centrado na escola e dirigido aos mais jovens) e a potencialização de todas as possibilidades de educação fora do tradicional sistema de educação escolar, onde os formandos, agentes ativos do seu processo formativo, experienciam simultaneamente o seu processo simbiótico de vida e de educação/formação, visando o pleno desenvolvimento da sua individualidade. Assim sendo, a educação enquanto um processo permanente e comunitário, a decorrer ao longo da vida de um indivíduo, pode e deve ser entendida como um "processo largo e multiforme que se confunde com o processo de vida de cada indivíduo" (CANÁRIO, 1999, p. 11), mediante o qual ele vai adquirindo habilidades e conhecimentos que lhe permitem uma confortável adequação às características próprias da faixa etária que vai experienciando, bem como uma efetiva participação na sociedade em que vive.

Em Portugal as práticas de educação de adultos que se desenvolvem no âmbito da educação formal, não obstante o papel relevante que assumem, representam apenas uma parte da enorme variedade de iniciativas de intervenção socioeducativa que, embora pouco reconhecidas socialmente, assumem um relevante papel na promoção da educação, na transformação social e na dinamização cultural (GUIMARÃES; SILVA; SANCHO, 2000; LIMA, 2007). Essas iniciativas de intervenção educativa não-formal, desenvolvendo-se em prol da transformação das condições de vida dos agentes sociais, 
partem e centram-se nos problemas existentes utilizando recursos humanos e materiais endógenos à comunidade, operacionalizando-se em projetos de desenvolvimento local ou de intervenção comunitária maioritariamente a cargo das várias organizações da sociedade civil (LIMA, 2007; MELO, 2006).

Enquanto um processo promotor de desenvolvimento humano integral e entendida como um direito na medida em que prepara para a melhor vivencia de cada uma das fases da vida, a educação na terceira idade, etapa em que as alterações das condições de vida são mais profundas, tem vindo a constituir-se um importante campo de ação no universo educacional. Mais do que a transformação dos tempos livres em oportunidades de educação/ aprendizagem, a educação na terceira idade, através de atividades artísticas, físicas e culturais (CACHIONI, 2003; VENTOSA, 2009), promove informações e conhecimentos bem como o desenvolvimento de capacidades motoras, mentais e de interação social que capacitam a população idosa para uma melhor adequação às alterações características dessa fase da vida. Considerando a agnição de que a capacidade cognitiva continua ativa mesmo na idade mais avançada (LEMAIRE; BHERER, 2012), muitos autores têm evidenciado a educação como fator determinante de um envelhecimento bem-sucedido (SIMÕES, 2006; VENTOSA, 2006; 2009; CUENCA CABEZA, 2004; OSÓRIO, 2008; PINTO, 2008; NERI, 2004; CACHIONI; NERI, 2004; JACOB; FERNANDES, 2011).

Corroborando o pensamento destes entre outros autores, nessas duas primeiras décadas do século XXI, também vários organismos internacionais têm vindo a atribuir à educação, entendida como um processo permanente e comunitário, um papel fundamental, enquanto instrumento promotor de capacidades com potencial para fazer face aos desafios da sociedade atual. Estes documentos apresentam medidas que se pretende sejam efetivamente implementadas, para que se torne possível desenvolver o potencial de todos os seres humanos independentemente da idade, gênero, raça ou condição social, com particular incidência na população adulta e adulta idosa, sensibilizando e recomendando, como sinaliza Patrício (2018), programas de educação/aprendizagem ao longo da vida; de educação para uma vida saudável; de sensibilização/informação/formação promotores de um prolongamento de vida ativa e participativa; de promoção do relacionamento intergeracional; do envelhecimento ativo; do acesso às novas tecnologias, etc., visando a aquisição de conhecimentos e capacidades que possibilitem o prolongamento de uma vida saudável, ativa e participativa (UNITED NATIONS, 2002, 2008; COMISSÃO DAS COMUNIDADES EUROPEIAS, 2002; COMISSÃO EUROPEIA, 2018a, 2018b; WORLD HEALTH ORGANIZATION, 2005, 2013; UNESCO, 2010).

A dinamização destes programas deve contemplar o desenvolvimento de todas as capacidades e habilidades humanas (literacia; ciência e tecnologia; digitais; linguísticas; pessoais e sociais; cívicas, empresariais e de expressão cultural e artística) no sentido de preparar para uma participação plena e efetiva na sociedade (COMISSÃO EUROPEIA, 2018b; PATRÍCIO, 2018).

Dentre essas novas habilidades, a literacia digital surge, nos nossos dias, como uma nova prioridade nos contextos e conteúdos dos processos de educação/aprendizagem e, em consequência, uma exigência que se impõe ao universo educativo. Um aspecto novo do direito à educação que deve abranger todas as idades, crianças, jovens, adultos e 
idosos (RODRÍGUEZ, 2008; PERÉZ TORNERO, 2013), no sentido de promover não só a integração no mercado de trabalho, mas também a coesão e participação social e cívica e o relacionamento intergeracional, evidenciando-se tão importante quanto a literacia e a numeracia. Quer em termos pessoais de comunicação e relação interpessoal, quer em termos profissionais, as tecnologias da informação e comunicação (TICs) desempenham, hoje, um papel predominante, fazendo parte do cotidiano individual, profissional e comunitário e, neste sentido, a aquisição de habilidades de literacia digital é considerada um fator determinante na adaptação e integração, de um modo especial dos adultos e idosos, na sociedade tecnológica digital dos nossos dias (RIBEIRO; MEDEIROS, 2016; CALVO et al., 2017; PEREIRA; NEVES, 2011; PÉREZ TORNERO, 2013; CARMO; ZAZZETA, 2016; EUROPEAN COMMISSION, 2012; EUROPEAN COMMISSION AGE, 2012).

Esse é, sem dúvida, o segmento populacional mais afetado pela revolução tecnológica digital, experienciando sérias dificuldades em lidar com os dispositivos tecnológicos e, consequentemente, impedida de usufruir dos seus benefícios, sentindo-se excluída deste processo evolutivo (PEREIRA e NEVES, 2011). Na sequência das recomendações internacionais, a par do que vem acontecendo nas sociedades desenvolvidas ou em vias de desenvolvimento, também em Portugal temos vindo a assistir à oferta de programas, projetos e iniciativas de promoção de habilidades digitais dirigidos a adultos e adultos idosos no sentido da infoinclusão desta faixa populacional e consequente usufruto dos benefícios dos avanços tecnológicos (GOMES, 2014).

A literacia digital em adultos idosos em situação de pré-reforma e reforma temse revelado um fator importante na promoção de um envelhecimento bem-sucedido, dado constituir uma nova forma de aceder à informação, a novas aprendizagens e conhecimentos, bem como facilitar a comunicação e relação com familiares e amigos, amenizando o isolamento e a solidão. A utilização das TICs, ao promover a participação ativa dos idosos na sociedade da informação, contribui para um aumento da autoestima, do sentimento de participação e pertencimento, resultando num aumento de autonomia, de integração social e satisfação, bem-estar e qualidade de vida (PALMA, 2013; PEREIRA; NEVES, 2011).

\section{Desenho e metodologia}

No âmbito do enquadramento das orientações teóricas enunciadas, foi desenvolvido um projeto de investigação-intervenção cuja finalidade se centrou na promoção do envelhecimento bem-sucedido centrado na estimulação físico-motora e cognitiva e na (re)ativação do relacionamento interpessoal com recurso às tecnologias de informação e comunicação (TICs).

\section{Caracterização do contexto}

0 projeto de investigação-intervenção, aqui apresentado, concretizou-se numa Instituição Particular de Solidariedade Social (IPSS) sediada no norte de Portugal, que 
promove, por meio de valências sociais em educação de adultos e gerontologia, o processo de educação/formação dos adultos idosos, contribuindo para a manutenção da sua autonomia e qualidade de vida.

\section{Participantes}

0 projeto abrangeu vinte e cinco (25) participantes, dezoito (18) do sexo feminino e sete (7) do sexo masculino, com idades compreendidas entre os cinquenta e seis (56) e os setenta e cinco (75) anos de idade.

A faixa etária do maior número de participantes, treze (13), situava-se entre os sessenta (60) e os setenta (70) anos. Treze (13) participantes eram casados; sete (7) viúvos; dois (2) solteiros, dois (2) divorciados e um não respondeu a essa questão.

Quanto às habilitações acadêmicas, quatro (4) participantes frequentaram, por períodos mínimos, a escola, não tendo obtido nenhum grau acadêmico; um (1) obteve o $3^{\circ}$ ano; doze (12) obtiveram o $4^{\circ}$ ano; cinco (5) obtiveram o $6^{\circ}$ ano; e três (3) obtiveram o $9^{\circ}$ ano. Relativamente à profissão, os participantes desempenharam atividades profissionais pouco qualificadas tais como: construção civil; costura; feirante; doméstica; motorista profissional etc.

\section{Métodos e instrumentos de recolha de dados}

0 paradigma de investigação que orientou este projeto de índole educativa foi o paradigma qualitativo interpretativo/hermenêutico, dado que este paradigma procura alcançar a compreensão dos fenômenos sociais e dos seus agentes. A sua linha de ação centra-se na descrição e interpretação das situações do cotidiano dos indivíduos, de modo a compreender as suas concepções e vivências, bem como o significado que lhes atribuem, visando a (trans)formação individual/coletiva, tornando-se os agentes sociais os protagonistas da sua própria mudança (SERRANO, 2004; BOGDAN; BIKLEN, 2013).

Os métodos subjacentes ao paradigma qualitativo, nomeadamente o etnográfico e a investigação-ação participativa constituíram os métodos orientadores do processo de investigação/intervenção. 0 método etnográfico, pressupondo uma observação e descrição pormenorizadas de elementos como a cultura, formas de vida e estrutura social, ajudou a compreender os comportamentos individuais/coletivos dos participantes e do contexto em que se inseriam (SERRANO, 2004). A investigação-ação participativa, enquanto uma metodologia que supõe simultaneamente a investigação e a ação e instiga a uma participação dos agentes sociais na resolução dos seus problemas através da consciencialização dos mesmos e da aquisição de conhecimentos e técnicas que possibilitem a transformação das situações e contextos (SERRANO, 2004; ANDER-EGG, 1990; BOGDAN; BIKLEN, 2013), foram entendidas como metodologias adequadas a um projeto de intervenção socioeducativa que se pretendia transformador de condições de vida.

Para recolha de dados fez-se uso de várias técnicas de investigação qualitativa como: observação direta e participante do tipo etnológico; inquérito por questionário; pesquisa e análise documental; conversas informais; diário de bordo e registo fotográfico. 
As atividades foram desenvolvidas por meio de técnicas de intervenção, nomeadamente técnicas de animação sociocultural, dado o seu caráter ativo e participativo. Atendendo à classificação de Ander-Egg (2000), foram utilizadas técnicas grupais, técnicas de informação/comunicação e técnicas para a realização de atividades lúdicas.

Relativamente ao processo de tratamento dos dados, a análise estatística descritiva simples ajudou a compreender as caraterísticas dos indivíduos e fenômenos sociais, objeto da nossa investigação/intervenção através do estudo de particularidades e procedimentos/ comportamentos regulares (PARDAL; LOPES, 2011) tais como a idade, o sexo, habilitações académicas e profissão. A análise de conteúdo foi importante para analisar os dados qualitativos provenientes das questões abertas do inquérito por questionário, permitindo uma análise sistematizada e organizada da informação seguindo as orientações de análise de conteúdo de Bardin (2014).

\section{Procedimentos}

0 trabalho de investigação/intervenção foi consolidado em três fases, incluindo cada uma delas diversos procedimentos:

I. Primeira fase - correspondeu ao período de inserção no contexto, abrangendo a realização da avaliação de diagnóstico, fase que durou dois meses e em que se procurou identificar os interesses, motivações, necessidades e potencialidades dos participantes com vista à concepção de um programa de intervenção potenciador de alterações positivas nas condições de vida dos participantes. Nesta fase foi, também, apresentado a todos os participantes o enquadramento institucional e a finalidade da intervenção, bem como as questões éticas inerentes ao mesmo, nomeadamente, o caráter voluntário da participação no estudo, a salvaguarda da identidade, a confidencialidade dos dados recolhidos e a divulgação (anônima) dos resultados.

II. Segunda fase - correspondeu ao período de planejamento e implementação da intervenção e durou aproximadamente dez meses. Após identificados os interesses, motivações, necessidades e potencialidades dos participantes, através da observação, das conversas informais e da análise dos dados do inquérito por questionário, que evidenciaram uma motivação e interesse particular pela informática, pela aquisição de informação/formação sobre vida saudável e temáticas atuais, procedeu-se à planificação da ação e das estratégias a desenvolver, de modo a alcançar a finalidade proposta: a promoção do desenvolvimento integral dos participantes, que se concretizou na dinamização de três oficinas: Oficina de Informática; Oficina Pedagógica e Vida Saudável; e Oficina Temática. 
Tabela 1 - Oficina de Informática

\section{OFICINA DE INFORMÁTICA - 17 Participantes}

\section{Objetivos}

- Capacitar para a utilização das novas tecnologias;

- Fortalecer a autoestima e 0 interesse de utilização das novas tecnologias;

- Promover a interação e comunicação;

- Estimular o exercício cognitivo.

\section{Atividades desenvolvidas}

- Iniciação à Informática - Explicação dos componentes de um computador de secretaria (teclado, mouse, monitor, etc.); distinguir hardware de software; explicar a evolução do computador; ligar/desligar; o ambiente de trabalho e atalhos; criação de pastas; a reciclagem.

- Introdução ao Microsoft Word - Copiar textos como prática de escrita; formatar textos através da exploração das ferramentas da "Base".

- Introdução à Internet - Compreender o que é uma ferramenta de busca e proceder a pesquisas na Internet.

- 0 Google Maps - Explorar locais de interesse pessoal: freguesia, cidade, país e locais onde estiveram ao longo da vida. Alguns participantes fizeram pesquisas sobre locais que gostariam de conhecer e alguns dos locais que foram visitados, nomeadamente, 0 jardim da Bacalhôa Buddha Eden.

- Como retirar e guardar conteúdo da Internet - Os participantes exploraram receitas saudáveis, e museus e sítios da cidade natal, como preparação das visitas a realizar.

- Criação e manutenção de conta de correio eletrônico - Os participantes criaram uma conta de correio eletrônico, com o intuito de trocarem informações, conteúdos e fotografias entre eles, com familiares e amigos. Em várias sessões praticaram o envio de fotografias e de ficheiros de texto entre eles, aprendendo a enviar e a fazer o download dos ficheiros.

- 0 Youtube - Os participantes fizeram pesquisa sobre músicas, receitas, episódios de telenovelas e outros programas de acordo com os gostos de cada um.

- Realização de jogo online: Kahoot-Atividade dedicada a um jogo de cultura geral online, em que cada participante tinha de selecionar a resposta correta a cada pergunta através do seu computador.

- Manusear e copiar ficheiros do pendrive, do celular e da máquina fotográfica - 0s participantes copiaram fotografias e ficheiros destes componentes para o computador e vice-versa.

- Acessar meios de comunicação online - em sessões distintas, os participantes acessaram meios de comunicação diferentes. No que se refere aos jornais, acessaram jornais locais e nacionais. Em relação às rádios os participantes deram preferência a rádios locais, abriram exceção à Rádio Comercial valorizando muito o fato de terem aprendido a acessar programas que já tinham sido apresentados e que não tiveram a oportunidade de ver.

- 0 chate as videochamadas - Através do correio eletrônico criou-se um chat, através do qual os participantes partilharam informações e realizaram videochamadas.

- Criação de uma conta de Facebook - Como mudar a foto de perfil; curtir e comentar; partilhar conteúdos; Acessar amigos e fazer pedidos de amizade; distinguir perfis de páginas; classificar páginas;

- Criação de uma conta de Dropbox - Guardar conteúdos online, que podem acessar em qualquer lugar, no celular, inclusive.

Fonte: Dados da pesquisa. 
Tabela 2 - Oficina Pedagógica e Vida Saudável

OFICINA PEDAGÓGICA E VIDA SAUDÁVEL - 12 Participantes

Objetivos

- Despertar a criatividade, os sentidos e a memória;

- Informar sobre a prevenção de doenças;

- Desenvolver sentimentos de companheirismo, amizade e partilha;

- Proporcionar momentos de aprendizagem, descoberta, diversão e relaxamento.

\section{Atividades desenvolvidas}

- Exercícios mentais - Os participantes realizaram exercícios que consistiram em completar palavras, decifrar um poema escrito com números, descobrir diferenças entre imagens, desvendar adivinhas e provérbios.

- Atividade: 0 que é a vida saudável? - Os participantes fizeram um brainstorming sobre o tema "vida saudável". Posteriormente compararam o brainstorming com definições de saúde, qualidade de vida, bem-estar, estilo de vida e vida saudável da OMS. Foram ainda abordados mitos e verdades sobre saúde.

- Alimentação com Glória - Jogo inventado que tem por base o jogo da Glória* mas realizado tendo como tema de fundo a alimentação saudável.

- A alimentação saudável: mitos e curiosidades - Esta sessão consistiu na exploração de dicas e curiosidades de uma alimentação saudável, na aprendizagem de leitura dos rótulos dos alimentos e na distinção de alimentos lights e diets.

- Pensamento lateral - Num primeiro momento a atividade teve uma dimensão mais expositiva, em que foi explicado em que consiste o pensamento lateral. 0 segundo momento consistiu na resolução de exercícios e enigmas para estimular o pensamento lateral.

- 0 Acidente Vascular Cerebral (AVC) - Esta atividade teve uma componente teórica e outra prática. A primeira foi dedicada à aquisição de informações sobre em que consiste um AVC, quais os sintomas a diagnosticar, causas e consequências. A segunda parte consistiu num exercício prático (água num copo, palhinhas e algodão) que exemplificava como um coagulo impede a circulação normal do sangue.

- 0 bingo - Foi uma atividade que visou o estímulo da concentração e da memória.

- Aula experimental de loga.

- Os sentidos - exploração dos sentidos olfato, paladar e visão.

- "Toca a mexer" - Exercícios físicos

- A comunicação: verbal e não-verbal - Inicialmente fez-se uma pequena explicação sobre o que é a comunicação. Depois foram trabalhados os vários tipos de comunicação não-verbal com dinâmicas que consistiram em transmitir uma mensagem através da comunicação não-verbal.

- Trabalho em equipe - Foram desenvolvidos vários jogos de estimulação cognitiva em que as equipes competiam entre si.

* 0 Jogo da Glória é um jogo de tabuleiro que pode realizar-se tendo por base qualquer tema. Neste caso o tema é a alimentação saudável. 0 jogador lança um dado e tem que responder à questão com o número indicado no dado, se acertar avança nas casas do tabuleiro para chegar à meta, se não acertar, recua o mesmo número de casas.

Fonte: Dados da pesquisa. 
Tabela 3 - Oficina Temática

OFICINA TEMÁTICA - 11 Participantes

Objetivos

- Fomentar um espaço de partilha e troca de cultura e valores;

- Promover novas aprendizagens/conhecimentos;

- Valorizar a história, vivências, cultura e saberes;

- Desenvolver o sentido crítico e a criatividade.

Atividades desenvolvidas

- Sessão sobre alimentação saudável - Sessão com nutricionista sobre alimentação saudável

- Palestra e debate sobre cuidados e proteção solar - Sessão de debate sobre a proteção solar (benefícios e malefícios do sol, a importância de nos protegermos do sol, dicas e curiosidades sobre o sol)

- Os 6 chapéus do pensamento - Sessão dedicada à dinâmica dos 6 chapéus de pensamento de Edward Bono. Esta atividade tinha como objetivo mostrar aos participantes como resolver problemas de uma forma criativa. A dinâmica consistia em respeitar a perspetiva do seu chapéu. Cada chapéu tinha uma cor e uma caraterística específica: o chapéu branco: apresenta os fatos; 0 chapéu azul: moderador; o chapéu preto: pontos negativos; o chapéu amarelo: oportunidades e benefícios; o chapéu vermelho: emoções e sentimentos; 0 chapéu verde: criatividade.

- Visitas - Foram realizadas algumas visitas culturais a locais e monumentos escolhidos pelos participantes.

Fonte: Dados da pesquisa.

III. Terceira fase - Avaliação - Trata-se de um procedimento que procura compreender e qualificar os resultados (erros e sucessos) da atividade investigação/intervenção, sendo transversal a todo o processo (SERRANO, 2008), e decorreu ao longo de doze meses.

$\mathrm{Na}$ fase inicial, a avaliação concretizou-se na identificação das necessidades, interesses e potencialidades, através de observação, das conversas informais e de um inquérito por questionário cujos dados permitiram conhecer os potenciais participantes, bem como compreender os seus interesses e motivações.

Num segundo momento realizou-se, através de inquérito por questionário, conversas informais e observação participante, a avaliação contínua. Este tipo de avaliação foi-se concretizando no decorrer da ação, procurando aferir se os processos e o caminho que se estava a seguir conduziam aos objetivos traçados (SERRANO, 2008), permitindo detectar problemas, possibilitando um mecanismo de autocorreção.

Por último, através de um inquérito por questionário, procedeu-se à avaliação final, procurando recolher dados que permitissem verificar se os objetivos foram alcançados com sucesso e quais os potenciais aspectos a melhorar. 


\section{Apresentação e discussão dos resultados}

Nesta parte do trabalho apresentam-se e discutem-se os resultados da avaliação final, obtidos a partir do inquérito por questionário, constituído por questões abertas e fechadas realizado aos participantes. Importa referir que se optou por agregar a informação tendo em conta as três categorias principais que emergiram do discurso dos participantes no que concerne ao impacto do projeto: "Aumento de Bem-estar"; "Aprendizagens" "Relacionamento Interpessoal/Convívio".

$\mathrm{Na}$ percepção dos participantes, o "Aumento de Bem-Estar" constituiu um dos maiores benefícios do projeto, dado ter proporcionado maior qualidade e satisfação com a vida como evidenciam os testemunhos seguintes: "Estar em boa companhia ajuda ao nosso bem-estar e a esquecer as nossas rotinas do dia a dia, pois para mim é melhor do que um calmante" (IQ11); "Sair de casa que não fazia muito, agora estou melhor "(IQ19); "Esta rotina ajudou-me a ficar mais alegre e com mais amizades, porque sou uma pessoa que gosta de conviver e sair de casa" (IQ1); "Fez-me superar alguns problemas de saúde" (IQ3); "Sair de casa, conviver mais, procurar sobre os assuntos aqui retratados"(IQ5); "A oficina contribuiu para que eu saísse de casa, para me sentir mais ativa” (IQ6).

Os testemunhos citados permitem inferir que a intervenção educativa não só contribuiu para atenuar o isolamento e inatividade da habitual rotina cotidiana, muito presentes nessa fase da vida, como promoveu o convivio e o relacionamento interpessoal, bem como uma atitude mais ativa e mais alegre que se traduz na percepção de um maior bem-estar e satisfação com a vida, indo ao encontro do pensamento de autores como (ANTUNES, 2016; ANTUNES; ABREU, 2017; SIMÕES, 2006; VENTOSA, 2006, 2009; CUENCA CABEZA, 2004; OSÓRIO, 2008; PINTO, 2008; NERI, 2004; CACHIONI; NERI, 2004; JACOB; FERNANDES, 2011), que entendem a intervenção educativa como fator determinante de um envelhecimento bem-sucedido.

A análise dos dados, considerando a percepção dos participantes, evidencia, também, as "Aprendizagens" como um dos pontos fortes do projeto. Todos os participantes inquiridos $(\mathrm{N}=17)$ referem ter adquirido novas aprendizagens indo ao encontro do pensamento dos defensores da ideia de que o potencial de desenvolvimento humano permanece ao longo da vida (LEMAIRE; BHERER; 2012; BALTES, 1987; BALTES; BALTES, 1990).

Quando se procurou apurar que tipo de aprendizagens os participantes tinham adquirido, emergiram duas subcategorias "conhecimentos gerais" e "conhecimentos de informática".

Os resultados parecem ir ao encontro do pensamento de autores como (SIMÕES, 2006; VENTOSA, 2006, 2009; CUENCA CABEZA, 2004; OSÓRIO, 2008; PINTO, 2008; NERI, 2004; CACHIONI; NERI, 2004; JACOB; FERNANDES, 2011), que defendem que mesmo na fase mais madura da vida se pode continuar a aprender como atestam as opiniões seguintes: "Aprendi muitas coisas que não sabia nem tinha ouvido falar, fiquei com a mente mais aberta, (...)” (IQ2); "Coisas novas que nem sabia existir" (IQ3); "Recordei muita coisa e aprendi outras novas (...)” (IQ1); “(...) foi bastante importante lembrar a História e outros temas” (IQ6); "Aprendi a ser mais independente, dar mais atenção às coisas, pôr as minhas ideias em prática” (IQ5); “ (...) aprender coisas que nunca pensei fazer na vida, é muito bom” (IQ17).

No enquadramento do pensamento de autores que aludem às novas necessidades educativas da sociedade tecnológica atual, nomeadamente no que diz respeito às 
Tecnologias da Informação e Comunicação (TICs) e, de um modo muito particular, nos adultos e adultos idosos (RIBEIR0; MEDEIROS, 2016; CALVO et al., 2017; PÉREZ TORNERO, 2013; CARMO; ZAZZETA, 2016; GOMES, 2014), a presente investigação contribuiu para a capacitação de habilidades digitais e infoinclusão de um grupo de pessoas deste segmento populacional, bem como apresentou resultados bastante positivos relativamente à aquisição de habilidades digitais na idade madura, tal como revelam os testemunhos que seguem: "Aprendi um pouco de tudo de informática e outras coisas" (IQ8); "Valeu a pena estar na oficina, aprendi e desenvolvi algum conhecimento sobre informática" (IQ12); "Valorizei as minhas competências informáticas" (IQ13); "Gostei um pouco de todas as aulas que frequentei e que me ajudaram a ter mais conhecimento dos computadores” (IQ16).

Corroborando a perspetiva dos autores acima referidos, Palma (2013) e Pereira e Neves (2011) fazem notar que a aquisição de habilidades digitais promovendo uma participação mais ativa dos idosos na sociedade contribui para um aumento da autoestima, integração social e satisfação com a vida, fato que este estudo também parece corroborar dado o aumento de bem-estar ter sido assinalado como o maior benefício do projeto.

$\mathrm{Na}$ percepção dos participantes, outro ponto forte do projeto foi o fato de ter promovido o "Relacionamento Interpessoal/Convívio", aspecto que, de uma forma ou de outra, aparece evidenciado no testemunho de todos os participantes, tendo sido sistematizado em duas subcategorias: "sair de casa e da rotina" e "convívio", como atestam as afirmações seguintes: "Além do ensinamento que me deu, contribuiu para que pudesse sair mais de casa e divertir-me" (IQ12); "Foi muito bom ter aparecido esta atividade, ajudou-me a ter horários e sair de casa. Foi muito bom" (IQ13); "Ocupou-me o tempo que precisava de preencher, ajudando a libertar o stress e a sair fora da rotina diária” (IQ16). "Contribuiu para aprender muito e conviver com todos os amigos" (IQ8); "Conheci pessoas novas, o convívio foi bom" (IQ3); "Conhecer vizinhos e conviver com outras pessoas" (IQ5); "Foi muita boa a convivência e o companheirismo" (IQ7); "Mudei muito, não saía de casa, comecei a sair mais, a conviver mais com outras pessoas” (IQ2).

Estes testemunhos, ao evidenciarem que um dos benefícios mais significativos da intervenção foi ter proporcionado o convívio e o aumento da rede de relações interpessoais, a criação de novos significados e objetivos de vida, reativar uma participação social ativa e participativa e amenizar o isolamento e passividade da rotina doméstica, reforçam de algum modo o pensamento de autores como (RIBEIRO; MEDEIROS, 2016; CALVO et al., 2017; PEREIRA; NEVES, 2011; PÉREZ TORNERO, 2013; CARMO; ZAZZETA, 2016), que entendem a aquisição de habilidades de literacia digital um fator importante na adaptação e integração social, de um modo especial dos adultos e idosos.

\section{Considerações finais}

Os resultados da presente intervenção educativa, embora não permitindo generalizações, dado o reduzido número da amostra e o fato de representarem dados de contexto, espaço e tempo determinados e limitados, parecem ir ao encontro da literatura ao evidenciarem a educação enquanto um instrumento poderoso para um envelhecimento bem-sucedido (SIMÕES, 2006; VENTOSA, 2006; OSÓRIO, 2008; PINTO, 2008; JACOB; FERNANDES, 2011, ANTUNES, 2016; ANTUNES; ABREU, 2017). 
Neste enquadramento, em primeira instância, importa mencionar que um aspecto referido por outros autores, que também se confirma neste estudo, é o fato de a intervenção educativa promover um aumento de bem-estar nos participantes (NERI, 2006; YASSUDA; SILVA, 2010; INOUYE et al., 2018). À semelhança dos autores acima referidos, também a intervenção educativa, aqui descrita, na medida em que promoveu oportunidades de novas aprendizagens; melhorou o funcionamento físico e mental; promoveu o convívio e o fortalecimento das redes de relações interpessoais e de afeto; possibilitou a reativação do sentimento de pertencimento e participação na comunidade, favorecendo a ressignificação das experiências e objetivos de vida, contribuiu para um aumento de bem-estar e maior satisfação com a vida.

Em segunda instância, os resultados permitem evidenciar que os seres humanos não só continuam a aprender mesmo na fase mais avançada da vida, como valorizam muito positivamente a participação em atividades de educação/aprendizagem. Estes resultados reforçam o movimento, já bastante presente nos dias de hoje, de estímulo à promoção e desenvolvimento de atividades educativas na terceira idade, fazendo jus à atual concepção de educação ao longo da vida proposta na literatura e em documentos nacionais e internacionais.

Em terceira instância, os resultados evidenciam, também, que a intervenção educativa favoreceu a promoção do convívio e o aumento da interação social, constituindo-se um importante fator de amenização das situações e sentimentos de isolamento e solidão, muito frequentes neste segmento da população. Neste sentido, e entendida como uma entre outras dinâmicas, a intervenção educativa contribuiu para amenizar dois problemas considerados como fatores de risco para a saúde da população idosa: o isolamento e solidão; tal como assinalam (BOSWORTH; SHAIE, 1997; FONTAINE, 2000; KRAUSE, 2001; PAÚL; FONSECA, 2005).

Em sintese, os resultados positivos do estudo corroboram a importância da intervenção educativa não formal junto à população idosa, enquanto instrumento promotor de conhecimentos e habilidades que capacitam para uma melhor adequação e adaptação ao processo de envelhecimento e velhice, constituindo mais uma experiência positiva que justifica a necessidade e urgência de reestruturação do sistema educativo, de forma a tornar-se capaz de promover a democratização da educação na e para a terceira idade, fator fundamental na promoção do envelhecimento bem-sucedido.

\section{Referências}

ABELES, Ronald; GIFT, Helen; ORY, Marcia. Aging and quality of life. New York: Springer, 1994.

ANDER-EGG, Ezequiel. Metodología y práctica de la animación sociocultural. Madrid: CCS, 2000.

ANDER-EGG, Ezequiel. Repensando la investigación - acción - participativa: comentarios, críticas y sugerencias. México, DC: El Ateneo, 1990.

ANTUNES, Conceição. A educação na terceira idade. In: ANTUNES Conceição; LEANDRO, Engrácia (coord.). Envelhecimento: perspetivas, projetos e práticas inovadoras. V. N. Famalicão: Humus, 2016. p. 51-66. 
ANTUNES, Conceição; ABREU, Vanessa. As novas tecnologias na promoção do envelhecimento bem sucedido. Ensino e Tecnologia em Revista, Londrina, v. 1, n. 1, p. 3-15, jan. /jun, 2017. https://doi. org/10.3895/etr.v1n15885

BALTES, Paul. Theoretical proposition of life-span developmental psychology: on the dynamic between grouth and decline. Development Psychology, Bowling Green, v. 32, n. 5, p. 611-626, 1987.

BALTES, Paul; BALTES, Margaret. Successful aging: perspectives from behavioral sciences. Cambridge: Cambridge University Press, 1990.

BARDIN, Laurence. Análise de Conteúdo. Lisboa: Edições 70, 2014.

BOGDAN, Robert; BIKLEN, Sari. Investigação qualitativa em educação: uma introdução à teoria e aos métodos. Porto: Porto Editora, 2013.

BOSWORTH, Hayden; SHAIE, Warner. The relationship of social environment, social networks and health outcomes in the Seattle Longitudinal study: two analytical approches. Journal of Gerontology, Boston, v. 52B, n. 5, p. 197-205, 1987.

CACHIONI, Meire. Quem educa os idosos? Um estudo sobre os professores de universidade da terceira idade. Campinas: Alínea, 2003.

CACHIONI, Meire; NERI, Anita. Educação e gerontologia: desafios e oportunidades. Revista Brasileira de Ciências do Envelhecimento Humano, Passo Fundo, v. 1, n. 1, p. 99-115, 2004. https://doi.org/10.5335/ rbceh.2012.49

CALVO, Inaki et al. Introducing computer-based concept mapping to older adults. Educational Gerontology, Philadelphia, v. 43, n. 8, p. 404-416, 2017. https://doi.org/10.1080/03601277.2017.1309635.

CANÁRIO, Rui. Educação de edultos: um campo e uma problemática. Lisboa: Educa, 1999.

CARMO, Gisele; ZAZZETTA, Marisa. Envelhecimento, novas tecnologias e aposentadoria. In: COSTA, José Luiz; COSTA, Amarilis; JUNIOR, Gilson. 0 que vamos fazer depois do trabalho? Reflexões sobre a preparação para aposentadoria. [S. I.: s. n.], 2016. p. 93-101. https://doi.org/10.7476/9788579837630

COMISSÃO DAS COMUNIDADES EUROPEIAS. Comunicação da Comissão ao Conselho e ao Parlamento Europeu: resposta da Europa ao envelhecimento da população mundial. Contribuição da Comissão Europeia para a II Assembleia Mundial sobre Envelhecimento. Bruxelas: CCE, 2002. Disponível em: https:// ec.europa.eu/transparency/regdoc/rep/1/2002/PT/1-2002-143-PT-F1-1.Pdf. Acesso em: 03 abr. 2021.

COMISSÃO EUROPEIA. Anexo da proposta de recomendação do Conselho da Europa sobre as competências essenciais para a aprendizagem ao longo da vida. Bruxelas: CE, 2018b. Disponível em: https://eur-lex.europa.eu/legal-content/PT/TXT/PDF/?uri=0J:C:2018:189:FULL. Acesso em: 03 abr. 2021.

COMISSÃO EUROPEIA. Proposta de recomendação do Conselho da Europa sobre as competências essenciais para a aprendizagem ao longo da vida. Bruxelas: CE, 2018a. Disponível em: https://eur-lex. europa.eu/legal-content/PT/TXT/PDF/?uri=0J:C:2018:189:FULL. Acesso em: 03 abr. 2021. 
CUENCA CABEZA, Manuel. Ócio e animação sociocultural: presente e futuro. In: TRILLA, Jaume (coord.) Animação sociocultural: teorias, programas e âmbitos. Lisboa: Instituto Piaget, 2004. p. 335-349.

DIAS, Isabel. 0 uso das tecnologias digitais entre os seniores: motivações e interesses. Sociologia, Problemas e Práticas, Lisboa, n. 68, p. 51-77, 2012.

DIAS, José Ribeiro. Educação: o caminho da nova humanidade. Porto: Papiro, 2009.

DIREÇ̃̃O GERAL DA SAÚDE. Plano Nacional de Saúde: revisão e extensão a 2020. Lisboa: Ministério da Saúde, 2015. Disponível em: http://1nj5ms2lli5hdggbe3mm7ms5-wpengine.netdna-ssl.com/ files/2015/06/Plano-Nacional-de-Saude-Revisao-e-Extensao-a-2020.pdf.pdf. Acesso em: 03 abr. 2021.

EUROPEAN COMMISSION. Health for growth: proposal for the 3r multi-annual programme 2014-2020. Bruxelas: CE, 2014. Disponível em: https://ec.europa.eu/health/programme/policy/proposal2014. Acesso em: 28 maio 2018.

EUROPEAN COMMISSION. ICT for seniors' and intergenerational learning: projects funded through the lifelong learning programme from 2008 to 2011. Brussels: Education, Audiovisual \& Culture Executive Agency, 2012. Disponível em: https://www.detales.net/wp/wp- content/uploads/2012/06/ict_ intergenerational_learning.pdf. Acesso em: 03 abr. 2021.

EUROPEAN COMMISSION AGE. Manifesto for an age-friendly European Union by 2020. Brussels: ECA, 2012. Disponível em: http://nmd.bg/wp-content/uploads/2014/01/4_ey2012_manifesto.pdf. Acesso em: 03 abr. 2021.

FERREIRA, Anderson et al. (org.). Educação e envelhecimento. Porto Alegre: Edipucrs, 2012.

FONTAINE, Roger. Psicologia do envelhecimento. Lisboa: Climepsi, 2000.

FUNDAÇÃO CALOUSTE GULBENKIAN. Um futuro para a saúde. Lisboa: Fundação Calouste Gulbenkian, 2014. Disponível em: https://content.gulbenkian.pt/wp-content/uploads/2016/03/30003652/PGIS_ BrochuraRelatorioCompletoHealthPortugues.pdf. Acesso em: 03 abr. 2021.

GOMES, Mara. Inclusão digital na terceira idade: a integração das TIC numa escola superior sénior. 2014. Dissertação (Especialização em Administração, Acompanhamento e Regulação da Educação) Universidade Lusófona de Humanidades e Tecnologias, Lisboa, 2014.

GUIMARÃES, Paula; SILVA, Olívia; SANCHO, Vitória. Educação/formação de adultos nas associações: iniciativas popularmente promovidas ou socialmente organizadas. In: LIMA, Lícinio (org.). Educação de adultos: Forum II. Braga: Universidade do Minho, 2000. p. 169-223. Unidade de educação de adultos.

HAZZARD, William Russel. Weight control and exercise: Cardinal features of successful preventive gerontology. Journal of the American Medical Association, Chicago, v. 274, n. 24, p. 1964-1965, 1995. http://dx.doi.org/10.1001/jama.1995.03530240074045 
INOUYE, Keika et al. Efeito da Universidade Aberta à terceira idade sobre a qualidade de vida do idoso. Educação e Pesquisa, São Paulo, v. 44, e142931, p. 1-19, 2018. http://dx.doi.org/10.1590/S16784634201708142931

JACOB, Luís. Animação de idosos: actividades. Porto: Âmbar, 2007.

JACOB, Luís; FERNANDES, Hélder. Ideias para um envelhecimento ativo. Almeirim: Rutis, 2011.

KRAUSE, Neal. Social support. In: BINSTOCK, Robert; GEORGE, Linda (ed.). Handbook of aging and the social sciences. San Diego: Academic Press, 2001. p. 272-294.

LEMAIR, Patrick; BHERER, Louis. Psicologia do envelhecimento: uma perspetiva cognitiva. Lisboa: Instituto Piaget, 2012.

LIMA, Lícinio. Educação ao longo da vida: entre a mão direita e a mão esquerda de Miró. São Paulo: Cortez, 2007.

MELO, Alberto. From the hills of the Algarve to the minister's Desk. In: CASTRO, Rui; SANCHO, Vitória; GUIMARÃES, Plaula (org.). Adult education: new routes in a new landscape. Braga: University of Minho, 2006. p. 167-188. Unity for Adult Education.

NERI, Anita. 0 legado de Paul B. Baltes à psicologia do desenvolvimento e do envelhecimento. Temas em Psicologia, Ribeirão Preto, v. 14, n. 1, p. 17-34, 2006.

NERI, Anita. Velhice bem sucedida. Campinas: Papirus, 2004.

OSÓRIO, Augustín. Animação sociocultural na terceira idade. In: PEREIRA, José; VIEITES, Manuel; LOPES, Marcelino (coord.). A animação sociocultural e os desafios do século XXI..Chaves: Intervenção, 2008. p. 207-219.

PALMA, Dora Isabel. 0 contributo das novas tecnologias para o bem-estar social dos idosos em meio rural: um estudo de caso. Beja: Instituto Politécnico de Beja, 2013.

PARDAL, Luís; LOPES, Eugénia. Métodos e técnicas de investigação social. Maia: Areal, 2011.

PATRÍCI0, Maria Raquel. Educação intergeracional no contexto sociocultural: contributos para um bom envelhecer. In: MAGALHÃES, Alexandra; PEREIRA, José; LOPES, Marcelino (coord.). A animação sociocultural e a educação intergeracional. Chaves: Intervenção, 2018. p. 141-147.

PAÚL, Constança; FONSECA, Manuel. Envelhecer em Portugal: psicologia, saúde e prestação de cuidados. Lisboa: Climepsi, 2005.

PEREIRA, Cláudia; NEVES, Rui. Os idosos na aquisição de competências TIC. Educação, Formação \& Tecnologia, Monte de Caparica/Almada, v. 4, n. 2, p. 15-24, 2011.

PÉREZ TORNERO, José Manuel. Comprender la alfabetizacíon digital: informe final EAC/76/03. Barcelona: UAB. 2013. Disponivel em: http://www.gabinetecomunicacionyeducacion.com/files/adjuntos/Comprender\%20 la\%20alfabetizaci_n\%20digital_informe\%20final_131204.pdf. Acesso em: 28 maio 2018. 
PINTO, Maria da Graça. Da aprendizagem ao longo da vida ou do exemplo de uma relação ternária: agora, antes, depois. Porto: FLUP, 2008. (Cadernos de apoio pedagógico da FLUP).

RIBEIRO, Carlos; MEDEIROS, Teresa. Educação sénior: a voz de estudantes adultos em idade avançada. In: MEDEIROS, Teresa (org.). (Re)pensar as pessoas idosas no século XXI. Ponta Delgada: Letras Lavadas, 2016. p. 241-264.

RIBEIRO, Óscar; PAÚL, Constança. Manual do envelhecimento activo. Lisboa: Lidel, 2011.

RODRÍGUEZ, Maria Dolores. Alfabetizacíon digital: el pleno dominio del lapis e el ráton. Comunicar, Huelva, v. 15, n. 30, p. 137-146, 2008.

ROWE, John; KAHN, Robert. Human aging: usual and successful. Science, Washington, DC, v. 237, n. 4811, p. 143-149, 1987.

ROWE, John; KAHN, Robert. Successful aging. New York, DTP Health, 1997a.

ROWE, John; KAHN, Robert. Successful aging. The Gerontologist, Oxford, v. 37, n. 4, p. 433-440, $1997 \mathrm{~b}$.

SERRANO, Glória. Elaboração de projectos sociais: casos práticos. Porto: Porto Editora, 2008.

SERRANO, Glória. Metodologias de investigação em animação sociocultural. In: TRILLA, Jaume (coord.). Animação sociocultural: teorias, programas e âmbitos. Lisboa: Instituto Piaget, 2004. p. 101-119.

SIMÕES, António. A nova velhice: um novo público a educar. Porto: Ambar, 2006.

UNESCO. Cinquième conférence internacionale sur l'éducación des adultes: la declaration d'Hambourg l'àgenda pou l'avenir. Hambourg: Unesco, 1997. Disponível em: https://unesdoc.unesco.org/ark:/48223/ pf0000116114_fre. Acesso em: 03 abr. 2021.

UNESCO. Conferencia de educação de adultos: marco de ação de Belém. Belém do Pará - Brasil. [S. I.]: Unesco, 2010. Disponível em: http://www.ceeja.ufscar.br/marco-acao-belem. Acesso em: 03 abr. 2021.

UNESCO. Recommendation on the development of adult education. Nairobi: Unesco, 1976. Disponível em: https://uil.unesco.org/fileadmin/keydocuments/AdultEducation/Confintea/en/Nairobi\%20Recommendation_ Eng.pdf. Acesso em: 03 abr. 2021.

UNITED NATIONS. Report of the conference, including the ministerial declaration - A society for all ages: challenges and opportunities. León: United Nations, 2008.

UNITED NATIONS. Report of the second world assembly on ageing. New York: United Nations, 2002.

VENTOSA, Victor. Animação sociocultural e terceira idade. In: PEREIRA, José; LOPES, Marcelino (coord.). A animação sociocultural na terceira idade. Amarante: Intervenção, 2009. p. 333-341.

VENTOSA, Victor. Perspectivas actuales de la animación sociocultural: cultura tiempo libre y participación cultural. Madrid: CCS, 2006. 
WORLD HEALTH ORGANIZATION. 8th Global conference on health promotion. Helsinki: WHO, 2013. Disponivel em: http://www.who.int/healthpromotion/ conferences/8gchp/statement_2013/en/. Acesso em: 10 dez. 2014.

WORLD HEALTH ORGANIZATION. Active ageing: a policy framework. [S. I.], WHO, 2002. Disponível em: https://apps.who.int/iris/handle/10665/67215. Acesso em: 03 abr. 2021.

WORLD HEALTH ORGANIZATION. Men, ageing and health: achieving health across the span. Geneve: OMS, 2001. Disponível em: https://apps.who.int/iris/bitstream/handle/10665/66941/WHO_NMH_ NPH_01.2.pdf?sequence=1. Acesso em: 03 abr. 2021.

WORLD HEALTH ORGANIZATION. Regional Office for Europe. Health 2020: A European policy framework and strategy for the 21st century. Copenhagen: WHO, 2013. Disponível em: https://www.euro.who.int/ data/assets/pdf_file/0011/199532/Health2020-Long.pdf. Acesso em: 03 abr. 2021.

WORLD HEALTH ORGANIZATION. Sixth conference on health promotion: the Bangkok charter for health promotion in a globalized world. Bangkok:WHO, 2005. Disponível em: https://www.who.int/healthpromotion/ conferences/6gchp/hpr_050829_\%20BCHP.pdf?ua=1. Acesso em: 03 abr. 2021.

YASSUDA, Mônica; SILVA, Henrique. Participação em programas para a terceira idade: impacto sobre a cognição, humor e satisfação com a vida. Estudos de Psicologia, Campinas, v. 27, n. 2, p. 207-214, 2010. http://dx.doi.org/10.1590/S0103-166X201000020008

ZIMERMAN, Guite. Velhice: aspectos biopsicossociais. Porto Alegre: Artmed, 2000.

Recebido em: 19.09.2019

Revisado em: 02.06.2020

Aprovado em: 21.07.2020

Maria da Conceição Pinto Antunes é doutora em filosofia da educação, pela Universidade do Minho, Braga, Portugal. Docente e investigadora da mesma instituição e diretora do Mestrado em Educação.

Ana Catarina Macedo é mestre em educação, área de especialização em educação de adultos e intervenção comunitária, pela Universidade do Minho Braga, Portugal. É técnica superior de educação na Cruz Vermelha Portuguesa - Delegação de Guimarães. 